\title{
Ultrastable PEGylated Calixarene-Coated Gold Nanoparticles with a Tunable Bioconjugation Density for Biosensing Applications
}

\author{
Maurice Retout, Pascale Blond, Ivan Jabin,* and Gilles Bruylants* \\ Cite This: Bioconjugate Chem. 2021, 32, 290-300 \\ Read Online
}

ABSTRACT: Many in vivo and in vitro applications using gold nanoparticles (AuNPs) require (i) their PEGylation, as it increases their stability and prevents nonspecific protein adsorption, and (ii) their conjugation to biomolecules, that provides them with specific recognition properties. Currently, the functionalization of AuNPs is based on thiol chemistry that suffers from two major drawbacks: (i) the $\mathrm{Au}-\mathrm{S}$ bond is labile and confers limited chemical robustness to the organic layer, and (ii) control over the bioconjugation density is highly challenging. We report here a

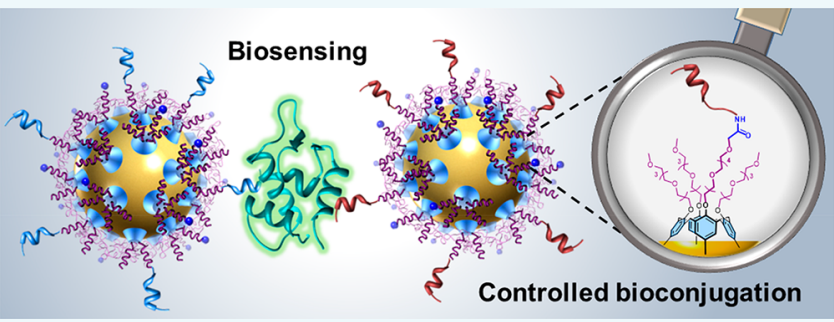
novel functionalization strategy based on calix[4]arene-tetradiazonium platforms for the coating of AuNPs with a robust PEG layer and their controlled bioconjugation. AuNPs were first modified with a functional calix[4]arene-diazonium salt bearing three PEG chains ended by a methoxy group and one by a carboxyl group. The resulting particles showed excellent chemical and colloidal stabilities, compared to similar systems obtained via a classical thiol chemistry, and could even be dispersed in human serum without degrading or aggregating. In addition to that, the carboxyl groups protruding from the PEG layer allowed their conjugation via amide bond formation with amine-containing biomolecules such as peptides. The control of the bioconjugation was obtained by grafting mixed layers of functional and nonfunctional PEGylated calix[4] arenes, that allowed varying the number of functional groups carried by the AuNPs and subsequently their bioconjugation capacity while preserving their dense protective PEG shell. Finally, we used these nanomaterials, modified with peptide aptamers, for the in vitro biosensing of a cancer biomarker, Mdm2.

\section{INTRODUCTION}

Nanomaterials and especially plasmonic nanoparticles are more and more studied in the biomedical field. ${ }^{1-3}$ This increasing interest lies in their remarkable chemical and optical properties resulting from their nanosize. ${ }^{4,5}$ In particular, gold nanoparticles (AuNPs) exhibit a localized surface plasmon resonance (LSPR) band in the visible region, which strongly depends on the dielectric properties of their local environment. ${ }^{6,7}$ In addition, several chemistries are known that allow their functionalization with a large variety of biomolecules (peptides, proteins, DNA, polymers, ....). ${ }^{8-12}$ These features gave rise to numerous developments as nanocarriers for in vivo drug delivery, ${ }^{13,14}$ hotspots for phototherapy, ${ }^{15,16}$ contrast agents for imaging systems, ${ }^{17,18}$ or colorimetric reporters for in vitro biosensing systems. ${ }^{19,20}$ For all these applications, AuNPs must be engineered to (i) possess sufficient chemical and colloidal stabilities and (ii) express specificity for target molecules or tissues. Indeed, when injected in vivo, AuNPs have to be biocompatible and to remain dispersed in physiological conditions or stable upon a pulsed-laser irradiation in the case of phototherapy or bioimaging. ${ }^{21,22}$ Moreover, AuNPs generally have to be functionalized with targeting ligands allowing them to interact with endogenous macromolecules, tissues, or cells. ${ }^{23}$ Similar modifications are required for in vitro biosensing as a limited stability of the AuNPs strongly affects the sensing performance and decoration with targeting ligands is mandatory to provide specificity for a given analyte. ${ }^{24,25}$ The PEGylation of AuNPs, that consists in covering the metallic gold core with hydrophilic and uncharged polyethylene glycol (PEG) chains, is often used to afford steric stabilization of the AuNPs as it limits their stability dependence on $\mathrm{pH}$ and ionic strength ${ }^{26}$ and confers them biocompatibility via stealth properties. Indeed, PEGylated AuNPs exhibit less protein nonspecific adsorption, a reduced uptake by the reticular endothelial system, and thus an increased in-blood circulation time. ${ }^{27,28}$ PEGs are commonly grafted on AuNPs via thiol groups as it is a very convenient grafting strategy based on the formation of $\mathrm{Au}-\mathrm{S}$ bonds. ${ }^{29-31}$ However, thiol chemistry possesses two severe drawbacks limiting their use for in vivo applications: (i) a limited chemical robustness of the organic layer due to the lability of the $\mathrm{Au}-\mathrm{S}$ bond $\mathrm{d}^{32,33}$ and (ii) the difficulty to control the grafting density of different thiolated molecules on the AuNP surface. ${ }^{34}$ An alternative strategy for the modification of

Received: December 7, 2020

Revised: January 4, 2021

Published: January 13, 2021 
surfaces consists in using aryl diazonium salts ${ }^{35}$ and in particular calix[4]arene-tetradiazonium salts. ${ }^{36}$ It has been shown that these molecular platforms can be strongly and irreversibly grafted onto various surfaces ${ }^{37}$ via the reduction of their diazonium groups that leads to the formation of multiple covalent bonds. ${ }^{38}$ Furthermore, thanks to their macrocyclic structure, no polymerization of these compounds is permitted at the surface, unlike the classical aryl diazonium salts. ${ }^{39}$ Recently, we showed that the grafting of calix[4]arenetetradiazonium salts could be extended to gold nanoparticles. ${ }^{40}$ The preparation of AuNPs with a thin but dense calixarenebased layer presenting remarkable colloidal and chemical stabilities was developed. Besides, as calix[4]arene-tetradiazonium salts differently substituted on the phenol positions possess a similar reactivity for gold surfaces, ${ }^{41}$ it was shown that the composition of mixed layers of calix[4]arenes could be controlled on AuNPs. ${ }^{42}$ In this work, we investigate the use of this grafting strategy for the development of dense and robust PEGylated AuNPs displaying a controlled number of bioconjugable groups at their surface. The PEGylation of AuNPs was obtained through the grafting of a functional calix[4] arene-tetradiazonium salt bearing four PEG chains: three ended by a methoxy group and one by a carboxylic acid $\left(\mathrm{X}_{4}-(\mathrm{PEG})_{4}-\mathrm{COOH}\right)$ (Figure 1$)$. We investigated the colloidal
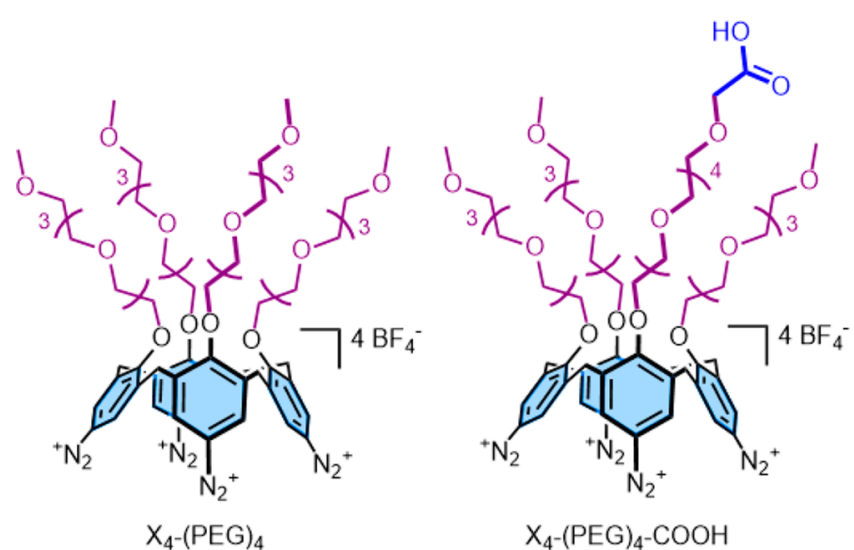

Figure 1. Structure of the calix[4]arene-tetradiazonium salts $\mathrm{X}_{4}$ $(\mathrm{PEG})_{4}$ and $\mathrm{X}_{4}-(\mathrm{PEG})_{4}-\mathrm{COOH}$. and chemical stabilities of AuNPs- $\mathrm{X}_{4}-(\mathrm{PEG})_{4}-\mathrm{COOH}$, and we compared them to those of AuNPs functionalized with a similar PEG but grafted via thiol chemistry (AuNPs-S-PEG$\mathrm{COOH})$. We then studied the simultaneous grafting of $\mathrm{X}_{4}$ $(\mathrm{PEG})_{4}-\mathrm{COOH}$ and of a nonfunctional calix[4] arene-tetradiazonium salt bearing four PEG chains, all ended by a methoxy group $\left(\mathrm{X}_{4}-(\mathrm{PEG})_{4}\right)$ (Figure 1$)$. We evaluated the reactivity of the carboxyl groups through conjugation of an organic dye, and we further confirmed the bioconjugation of peptide aptamers with different grafting densities. Finally, we investigated the use of such AuNPs conjugated to peptide aptamers for the biosensing of a human cancer biomarker, the $\mathrm{Mdm} 2$ protein, ${ }^{43}$ and evaluated the improvement compared to a previously reported system based on thiol chemistry. ${ }^{44}$

\section{RESULTS AND DISCUSSION}

Optimization of the Grafting of $\mathrm{X}_{4}-(\mathrm{PEG})_{4}-\mathrm{COOH}$. The grafting of $\mathrm{X}_{4}-(\mathrm{PEG})_{4}-\mathrm{COOH}$ by ligand exchange was optimized on citrate-capped gold nanoparticles (AuNPscitrate) of $17 \mathrm{~nm}$ synthesized via an adapted Turkevich method (Figure S1A). The grafting procedure was inspired from what was previously described in the literature with closely related calix[4]arene-tetradiazonium salts (Scheme 1). ${ }^{42}$ Briefly, an aqueous solution of $\mathrm{X}_{4}-(\mathrm{PEG})_{4}-\mathrm{COOH}$ was slowly added to the AuNPs-citrate in the presence of $\mathrm{NaBH}_{4}$ (approximately 100 calix[4] arenes per $\mathrm{nm}^{2}$ and 0.5 equiv of $\mathrm{NaBH}_{4}$ per calix[4]arene) and the resulting AuNPs coated with $\mathrm{X}_{4}$ - $(\mathrm{PEG})_{4}-\mathrm{COOH}$ (i.e., AuNPs- $\left.\mathrm{X}_{4}-(\mathrm{PEG})_{4}-\mathrm{COOH}\right)$ were washed through successive centrifugations. The grafting of $\mathrm{X}_{4}-(\mathrm{PEG})_{4}-\mathrm{COOH}$ was also achieved on citrate/tannic acidcapped AuNPs of $13 \mathrm{~nm}$ synthesized via a seeds-growth method (Figure S1C) in order to demonstrate the versatility of the functionalization strategy.

The resulting AuNPs- $\mathrm{X}_{4}-(\mathrm{PEG})_{4}-\mathrm{COOH}$ were characterized by various methods such as TEM, TGA, DLS, IR, and UV-vis. TEM images showed no change in the size or shape of the AuNP metallic core after the grafting of $\mathrm{X}_{4}-(\mathrm{PEG})_{4}-\mathrm{COOH}$ as well as no signs of aggregation during the functionalization step (Figure $2 \mathrm{a}$ vs $2 \mathrm{~b}$ ). Moreover, the interparticular distance increased after functionalization, to reach approximately $4 \mathrm{~nm}$ (Figures $2 \mathrm{a}$ and $2 \mathrm{~b}$, insets), which is in good agreement with the thickness of the calix[4] arene layer, that is approximately 2 $\mathrm{nm}$ if the PEG chains are extended. UV-vis analysis of the

Scheme 1. Schematic Representation of the Grafting of $\mathrm{X}_{4}-(\mathrm{PEG})_{4}-\mathrm{COOH}$ on AuNPs via Ligand Exchange and of the Conjugation of a Cyanine7.5 Amine Dye to the AuNPs- $\mathrm{X}_{4}-(\mathrm{PEG})_{4}-\mathrm{COOH}$ via an EDC/sulfo-NHS Procedure ${ }^{a}$

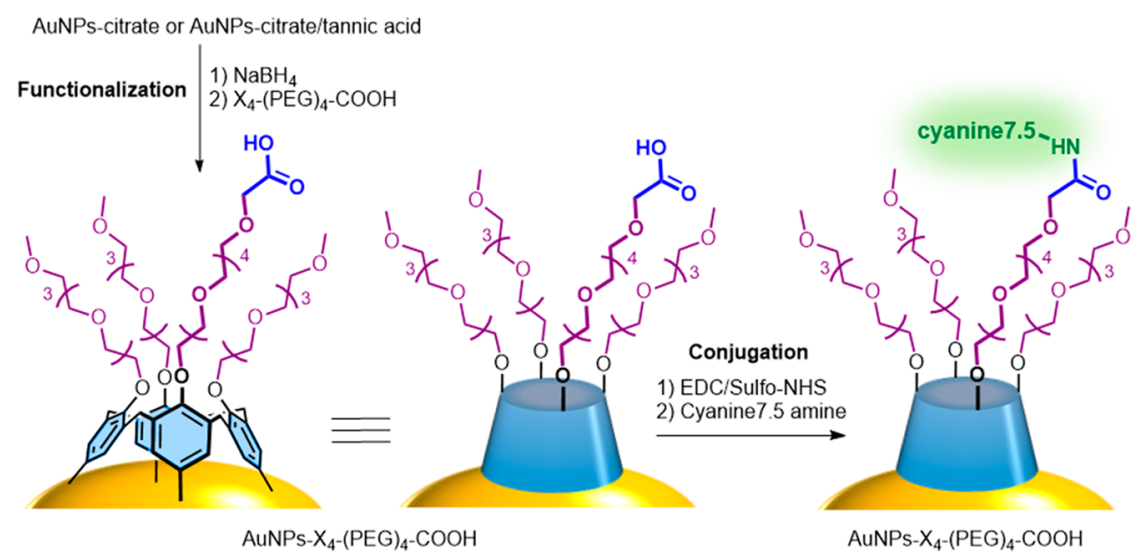

${ }^{a}$ Note that the representation of the grafted calixarene does not necessarily imply that its four aryl units are linked to the surface. 


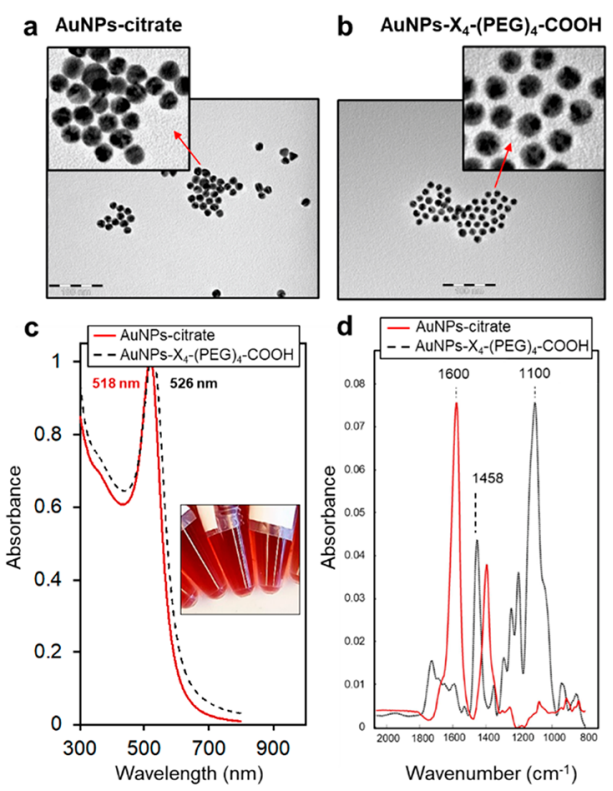

Figure 2. (a) TEM images of AuNPs-citrate and (b) AuNPs- $\mathrm{X}_{4}$ $(\mathrm{PEG})_{4}-\mathrm{COOH}$. Insets show a zoom of the arrow-indicated zones. (c) $\mathrm{UV}$-vis spectra of AuNPs-citrate dispersed in water (red plain line) and AuNPs- $\mathrm{X}_{4}-(\mathrm{PEG})_{4}-\mathrm{COOH}$ dispersed in physiological buffer (black dashed line). The inset shows a picture of AuNPs- $\mathrm{X}_{4}$ (PEG) ${ }_{4}-\mathrm{COOH}$ suspensions. (d) IR spectra of AuNPs-Citrate (red plain line) and AuNPs- $\mathrm{X}_{4}-(\mathrm{PEG})_{4}-\mathrm{COOH}$ (black dashed line).

AuNPs- $\mathrm{X}_{4}-(\mathrm{PEG})_{4}-\mathrm{COOH}$ dispersed in a physiological solution (phosphate buffer $10 \mathrm{mM}$ at $\mathrm{pH}$ 7.4; $150 \mathrm{mM} \mathrm{NaCl}$ ) revealed a sharp LSPR band, indicating well-dispersed particles (Figure 2c). This was confirmed by the bright red color of the suspension (Figure 2c, inset). A shift of the $\lambda_{\max }$ of approximately $8 \mathrm{~nm}$, from 518 to 526 , was observed upon functionalization. IR spectroscopy revealed the presence of calix[4]arenes on the particles AuNPs- $\mathrm{X}_{4}-(\mathrm{PEG})_{4}-\mathrm{COOH}$, as signals of aromatics ring stretching at $1458 \mathrm{~cm}^{-1}$ and asymmetrical $\mathrm{C}-\mathrm{O}-\mathrm{C}$ stretching of the PEG chains at 1100 $\mathrm{cm}^{-1}$ could be clearly observed (Figure $2 \mathrm{~d}$ ) (for comparison, see the IR spectrum of $\mathrm{X}_{4}-(\mathrm{PEG})_{4}-\mathrm{COOH}$, Figure S3). In addition to that, no signals of remaining citrate anions $\left(\mathrm{COO}^{-}\right.$ asymmetrical and symmetrical at 1600 and $1390 \mathrm{~cm}^{-1}$, respectively) were observed, indicating that the ligand exchange was efficient. It is worth mentioning that the carboxylate groups of the calixarene layer cannot be observed in the IR spectrum of the AuNPs- $\mathrm{X}_{4}-(\mathrm{PEG})_{4}-\mathrm{COOH}$ because these groups are present in low amounts and at a large distance from the metallic core, which means that they do not strongly benefit from the enhancement effect of the particles. ${ }^{45}$

TGA analysis revealed a grafting density of approximately 1.6 calix[4]arenes $/ \mathrm{nm}^{2}$. Regarding the theoretical area occupied by a calix[4] arene $\left(0.7 \mathrm{~nm}^{2}\right)$, this grafting density corresponds to a thin organic layer around the particles. A grafting density of 1.6 calix[4]arenes $/ \mathrm{nm}^{2}$ implies the presence of more than 6 PEG chains $/ \mathrm{nm}^{2}$ at the surface, which is higher than the grafting density obtained by grafting HS-PEG derivatives of similar chain length ( $\sim 4$ HS-PEG chains/ $\left.\mathrm{nm}^{2}\right) .{ }^{46}$ The TGA curve and full calculations can be found in the Supporting Information (Figure S4 and Table S1). The thin coating was confirmed by DLS, that revealed an increase of the average hydrodynamic diameter from $28.2 \pm 1.5 \mathrm{~nm}$ (polydispersity index $(\mathrm{PDI})=0.42)$ for the initial AuNPs- citrate to $40.5 \pm 1.5 \mathrm{~nm}(\mathrm{PDI}=0.40)$ for $\mathrm{AuNPs}^{-\mathrm{X}_{4^{-}}}(\mathrm{PEG})_{4^{-}}$ $\mathrm{COOH}$. This value is slightly higher than that $(32 \pm 2.5 \mathrm{~nm}$, PDI $=0.38)$ obtained for AuNPs covered with a PEG layer obtained via the chemisorption of HS-PEG-COOH whose length is similar to that of $\mathrm{X}_{4}-(\mathrm{PEG})_{4}-\mathrm{COOH}$ (Figures S5-7). It could be explained by the confinement of the PEG chains on the calixarene platform and by the higher density of PEG obtained for AuNPs- $\mathrm{X}_{4}-(\mathrm{PEG})_{4}-\mathrm{COOH}$ than for AuNPs-SPEG-COOH, that force the PEG chains in a more extended conformation.

Stability Evaluation of AuNPs- $\mathrm{X}_{4}-(\mathrm{PEG})_{4}-\mathrm{COOH}$. For comparison purpose, the colloidal stability of AuNPs-S-PEG$\mathrm{COOH}$ and AuNPs- $\mathrm{X}_{4}-(\mathrm{PEG})_{4}-\mathrm{COOH}$ and the chemical robustness of their PEG shell were evaluated in-depth by $\mathrm{UV}$-vis spectroscopy. In acidic conditions ( $\mathrm{pH} 2)$, both types of NP aggregate due to the protonation of the carboxylate groups. In contrast to what is observed for citrate capped AuNPs, this aggregation is however reversible thanks to the dense PEG shell that sterically protects the AuNP cores from irreversible aggregation (Figures $3 a$ and $3 b$ ). The impact of the temperature on the robustness of the organic layer was then evaluated. At $65{ }^{\circ} \mathrm{C}$, AuNPs-S-PEG-COOH were degraded after a few hours (Figure 3d), indicating a detachment of the thiol groups from the surface, while barely any variation of the LSPR band was observed for AuNPs- $\mathrm{X}_{4}-(\mathrm{PEG})_{4}-\mathrm{COOH}$ (Figure 3c). We pushed further the physical stress by drying the AuNPs before resuspending them in water. Again, AuNPs$\mathrm{X}_{4^{-}}(\mathrm{PEG})_{4}-\mathrm{COOH}$ were barely affected by this process while it was not possible to redisperse AuNPs-S-PEG-COOH (Figures $3 \mathrm{e}$ and $3 \mathrm{f}$ ). All these results show that the calix[4]arene-based PEG shell is more strongly anchored to the AuNP surface, thanks to the multiple $\mathrm{Au}-\mathrm{C}$ bonds that the calix[4]arene can make with the gold surface, as well as to the irreversible nature of the $\mathrm{Au}-\mathrm{C}$ bond compared to the labile $\mathrm{Au}-\mathrm{S}$ bond. ${ }^{47-49}$ Finally, AuNPs- $\mathrm{X}_{4}-(\mathrm{PEG})_{4}-\mathrm{COOH}$ were suspended in human serum. After $1 \mathrm{~h}$ of incubation, the serum was removed by centrifugation and the UV-vis spectrum of the AuNPs resuspended in water showed no aggregation or degradation of the AuNPs (Figure S8). This result indicates that the calixarene-coated AuNPs can be used in physiological conditions, opening the door to their in vivo use.

Conjugation of (Bio)molecules to AuNPs- $\mathrm{X}_{4}-(\mathrm{PEG})_{4}{ }^{-}$ $\mathrm{COOH}$. In addition to ensuring a strongly anchored PEG shell, the coating with $\mathrm{X}_{4}-(\mathrm{PEG})_{4}-\mathrm{COOH}$ can be used for conjugation of ligands to the AuNPs. The reactivity of the carboxyl groups at the surface of AuNPs- $\mathrm{X}_{4}-(\mathrm{PEG})_{4}-\mathrm{COOH}$ was evaluated by the conjugation of an amino-dye (cyanine7.5 amine, see Figure S9b) via the classical EDC/sulfo-NHS procedure (Scheme 1). This dye strongly absorbs light in a region of the spectrum where the absorbance of the dispersed particles is negligible $\left(\lambda_{\max }=805 \mathrm{~nm}\right.$; ext. coeff. $=223.000$ $\mathrm{cm}^{-1} \mathrm{~mol}^{-1} \mathrm{~L}^{-1}$ ), which allows its direct quantification on the NPs by UV-vis absorption spectroscopy (see Figure S9a for its UV-vis spectrum). Control experiments in the absence of coupling reagents (EDC/sulfo-NHS) were also performed to confirm the covalent binding of the dye (Figure 4). Detailed description of the quantification procedure is given in the Experimental Section. An average conjugation density of 0.56 \pm 0.07 dye per $\mathrm{nm}^{2}$ covalently bound to AuNPs- $\mathrm{X}_{4^{-}}(\mathrm{PEG})_{4^{-}}$ $\mathrm{COOH}$ was measured. This value corresponds to the difference between the densities determined in the presence and in the absence of the coupling agents. Despite the many cleanings of the AuNPs using sodium dodecyl sulfate (SDS), a 
AuNPs- $\mathrm{X}_{4}-(\mathrm{PEG})_{4}-\mathrm{COOH}$ AuNPs-S-PEG-COOH

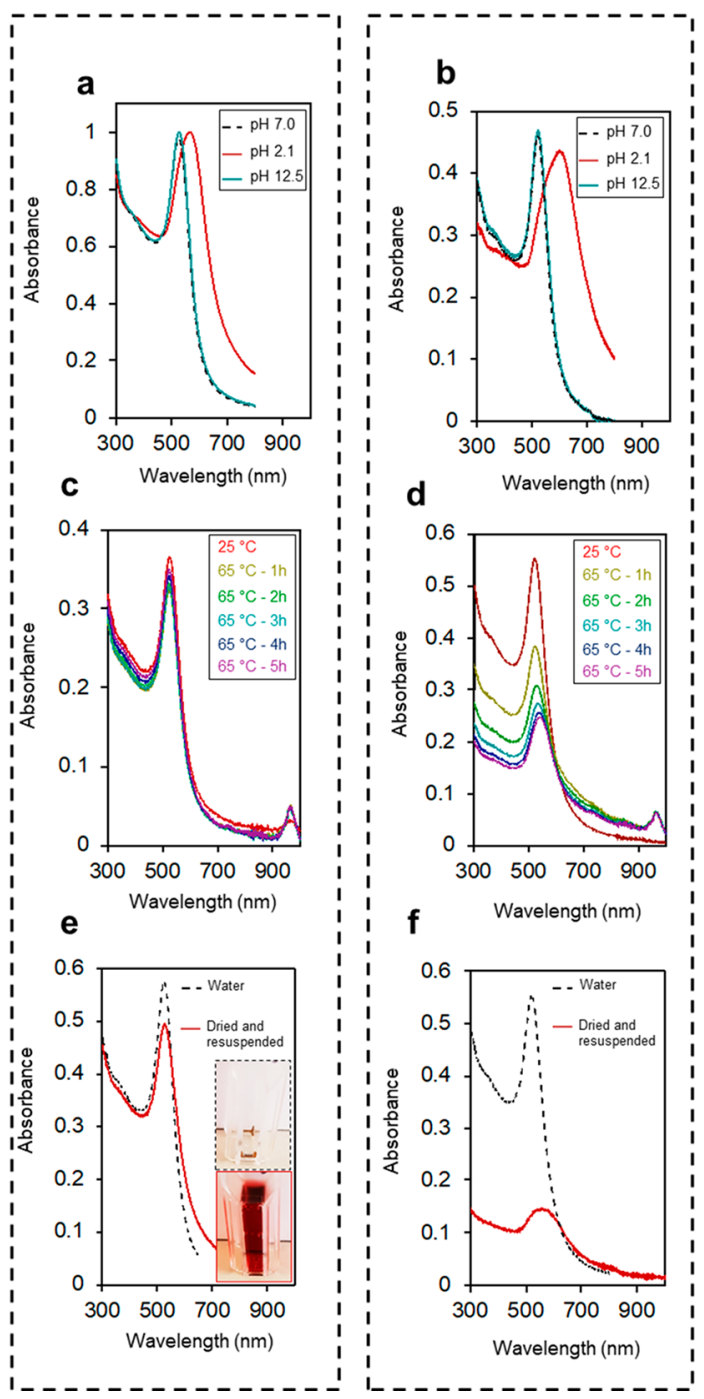

Figure 3. UV-vis spectra of (a) AuNPs- $\mathrm{X}_{4}-(\mathrm{PEG})_{4}-\mathrm{COOH}$ and (b) AuNPs-S-PEG-COOH suspended in water first at $\mathrm{pH} 7$, then $\mathrm{pH} 2$, and finally $\mathrm{pH} 12$. UV-vis spectra of (c) AuNPs- $\mathrm{X}_{4}-(\mathrm{PEG})_{4}-\mathrm{COOH}$ and (d) AuNPs-S-PEG-COOH suspended in water at $65{ }^{\circ} \mathrm{C}$ over time. UV-vis spectra of (e) AuNPs- $\mathrm{X}_{4}-(\mathrm{PEG})_{4}-\mathrm{COOH}$ and (f) AuNPs-S-PEG-COOH before (black dashed line) and after (red plain line) drying and resuspension in water.

small amount of the dye was observed on the AuNPs even in the absence of EDC/sulfo-NHS. This residual amount can be explained by the trapping of the dye in the dense PEG shell. An approximate value of 0.3 dyes per carboxylate can be determined by comparing the dye grafting density to that of the calixarene determined by TGA $\left(1.6\right.$ calix $[4]$ arenes $\left./ \mathrm{nm}^{2}\right)$. This data shows that AuNPs- $\mathrm{X}_{4}-(\mathrm{PEG})_{4} \mathrm{COOH}$ can be functionalized with a significant amount of molecules possessing an amino group while preserving their colloidal stability, even when hydrophobic molecules are conjugated. For comparison, similar conjugation of the cyanine7.5 amine was performed with AuNPs-S-PEG-COOH and a dramatic loss of the colloidal stability, characterized by the broadening of the LSPR band, was observed (Figure S10). This drastic difference of stability highlights the superiority of our calix [4]arene-based strategy over the standard thiol-based chemistry for the functionalization of AuNPs. It is interesting

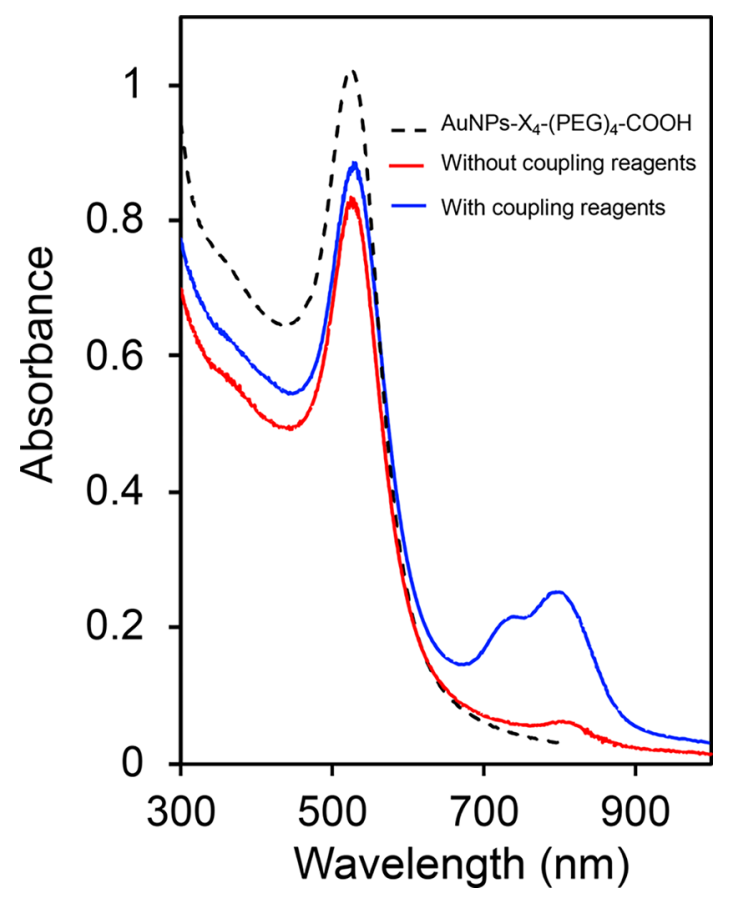

Figure 4. UV-vis spectra of AuNPs- $\mathrm{X}_{4}-(\mathrm{PEG})_{4} \mathrm{COOH}$ (black dashed line) to which the cyanine7.5 amine dye has been coupled, in the presence (blue line) and in the absence (red line) of EDC and sulfo-NHS reagents.

to point out that, despite the larger density of carboxylate groups for AuNPs-S-PEG-COOH than for AuNPs- $\mathrm{X}_{4}-(\mathrm{PEG})_{4^{-}}$ $\mathrm{COOH}$ (3.5 vs 1.6 carboxylate groups per $\mathrm{nm}^{2}$ ), similar grafting densities were estimated, respectively 0.65 and 0.56 grafted dye $/ \mathrm{nm}^{2}$ (due to the aggregation of the AuNPs-S-PEG$\mathrm{COOH}$ upon conjugation of the dye this value is only an estimate), indicating a higher conjugation yield in the latter case.

We further investigated the bioconjugation of two peptides (named p53 and p14, Figure S11) that can specifically recognize the oncoprotein $\mathrm{Mdm} 2$, a human cancer biomarker. The two peptides possess a similar size but differ by their charge and their hydrophilicity: p53 is negatively charged while p14 is positively charged and more lipophilic. Due to its numerous positive charges ( 14 contains four arginine and one lysine residues), the grafting of p14 onto negatively charged particles such as AuNPs-citrate or AuNPs-S-PEG-COOH represents a strong challenge. In a previous study, we developed a sandwich assay for the detection of $\mathrm{Mdm} 2$ based on the aggregation of two batches of AuNPs conjugated respectively to $\mathrm{p} 53$ and $\mathrm{p} 14$ via thiol groups. ${ }^{44}$ However, it was shown that the grafting of more than 50 p14 peptides via a thiol chemistry onto AuNPs-citrate $(16 \mathrm{~nm})$ led to the irreversible aggregation of the particles due to the modification of their surface potential. In addition to that, AuNPs covered by only ca. 50 p14 peptides were not sufficiently stable to be dispersed in physiological fluids and the detection could only be performed in low ionic strength media.

We investigated the grafting of p14 onto AuNPs-S-PEG$\mathrm{COOH}$ via the classical EDC/sulfo-NHS coupling procedure. Thanks to the PEG layer, a large excess of p14 (up to 2000 $\mathrm{p} 14 / \mathrm{NP}$ ) could be added to the particle suspension in order to maximize bioconjugation. However, the resulting particles could not be cleaned from the excess of reagents as they 

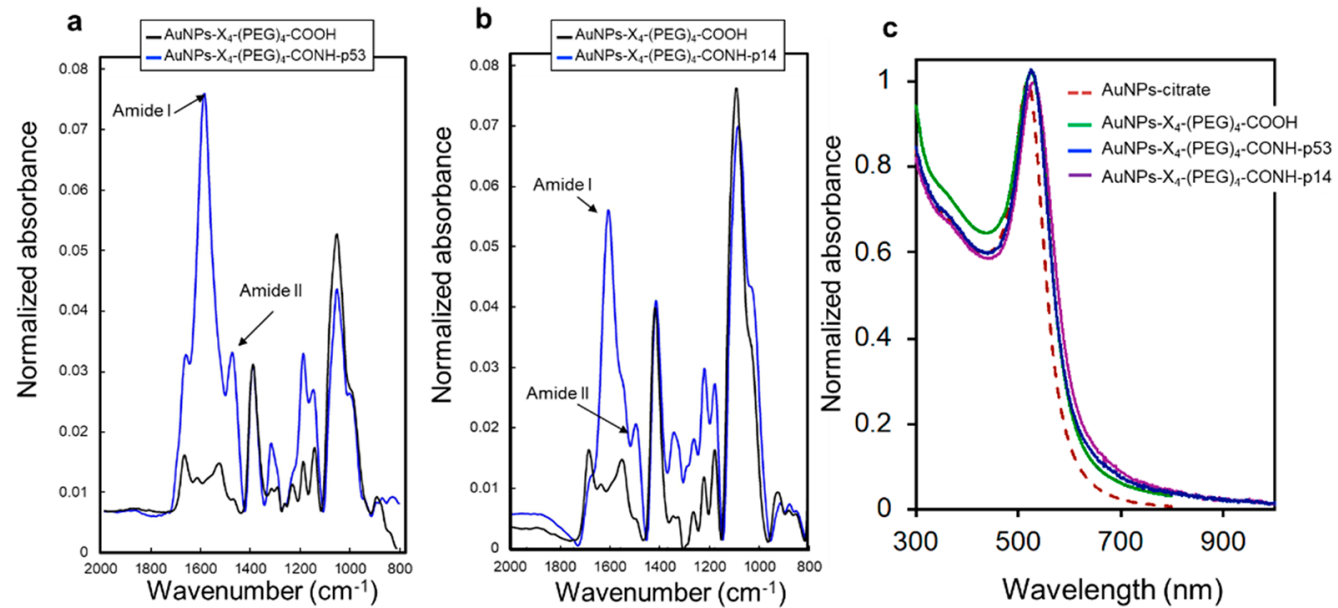

Figure 5. (a) IR spectra (normalized at $1458 \mathrm{~cm}^{-1}$ ) of AuNPs- $\mathrm{X}_{4}-\mathrm{PEG}_{4}-\mathrm{COOH}$ before (black) and after (blue) coupling of (a) the p53 peptide and (b) the p14 peptide. (c) UV-vis spectra of AuNPs-citrate (dashed red), AuNPs- $\mathrm{X}_{4}-(\mathrm{PEG})_{4}$-COOH (plain green), AuNPs- $\mathrm{X}_{4}-(\mathrm{PEG})_{4}$-CONHp53 (plain blue), and AuNPs- $\mathrm{X}_{4}-(\mathrm{PEG})_{4}-\mathrm{CONH}-\mathrm{p} 14$ (plain pink) dispersed in water.

Scheme 2. Schematic Representation of the Functionalization of AuNPs with Different Mixtures of $\mathrm{X}_{4}-(\mathrm{PEG})_{4}$ - $\mathrm{COOH}$ and $\mathrm{X}_{4}$ $(\mathrm{PEG})_{4}{ }^{a}$

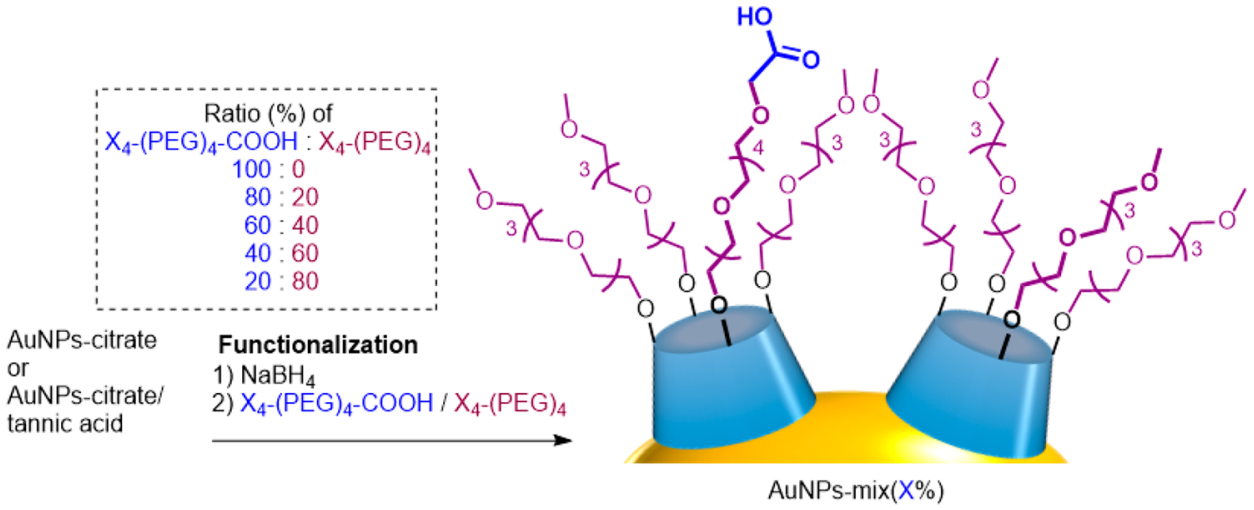

${ }^{a}$ Note that the particles are labeled according to the proportion of $\mathrm{X}_{4^{-}}(\mathrm{PEG})_{4}-\mathrm{COOH}$ added during the functionalization step.

irreversibly aggregated during the centrifugation cycles. The bioconjugation of both peptides was then performed on AuNPs- $\mathrm{X}_{4}-(\mathrm{PEG})_{4}-\mathrm{COOH}$ in similar conditions (see the Experimental Section). The success of the coupling procedure was evidenced by IR spectroscopy after appropriate washing of the particles. Figure 5a and $5 \mathrm{~b}$ shows the IR spectra of AuNPs$\mathrm{X}_{4}-(\mathrm{PEG})_{4}-\mathrm{COOH}$ to which either p53 (AuNPs- $\mathrm{X}_{4}-(\mathrm{PEG})_{4}$ CONH-p53) or p14 (AuNPs- I $_{4}$ (PEG) $)_{4}$-CONH-p14) has been conjugated. In both cases, we can clearly observe the amide-I $\left(\sim 1650 \mathrm{~cm}^{-1}\right)$ and amide-II $\left(\sim 1540 \mathrm{~cm}^{-1}\right)$ absorbance bands as well as typical bands corresponding to p53 and p14 (see Figure S12), confirming the presence of the peptides on the particles. Control bioconjugation experiments without coupling agents were performed and did not reveal any nonspecific adsorption of these peptides on the particles. It is worth mentioning that the dispersibility of the AuNPs was not affected after the bioconjugation of the two peptides (Figure $5 c)$. As mentioned above, the efficient coupling of the p14 peptide constitutes a remarkable result that allows functionalization of the same particles with oppositely charged peptides and mixing them in physiological conditions without loss of colloidal stability.

Tunable Bioconjugation. After having demonstrated the conjugation of biomolecules to AuNPs- $\mathrm{X}_{4}-(\mathrm{PEG})_{4}-\mathrm{COOH}$, we decided to set up a strategy allowing easy tuning of the bioconjugation density while preserving the dense PEG shell around the particles. Indeed, some applications require control over the grafting density of biomolecules at the nanoparticle surface. Our method consists in grafting a mixed layer of two calixarenes, i.e. $\mathrm{X}_{4^{-}}(\mathrm{PEG})_{4}-\mathrm{COOH}$ and one bearing four PEG chains ended by a methoxy group $\left(\mathrm{X}_{4}-(\mathrm{PEG})_{4}\right)$ (Figure 1$)$, in order to control the number of bioconjugable carboxylate groups protruding from the PEG shell. As already mentioned, it was described that calix[4]arene-tetrediazonium salts differently substituted on the phenol positions possess a similar reactivity for gold surfaces (vide supra). ${ }^{42}$ Therefore, it was expected that $\mathrm{X}_{4}-(\mathrm{PEG})_{4}-\mathrm{COOH}$ and $\mathrm{X}_{4}-(\mathrm{PEG})_{4}$ would be grafted on the gold surface in the same proportions than those used in the functionalization medium.

The grafting of mixed layers of calix $[4]$ arenes $\mathrm{X}_{4}-(\mathrm{PEG})_{4}$ $\mathrm{COOH}$ and $\mathrm{X}_{4}-(\mathrm{PEG})_{4}$ on AuNPs was investigated on three distinct batches of AuNPs, differing by their size, synthetic procedure, and capping-agents (Scheme 2). More precisely, two batches of citrate-capped AuNPs with an average size of respectively 17 and $14 \mathrm{~nm}$ were produced via the Turkevich method, and one batch of citrate/tannic acid-capped AuNPs with an average size of $13 \mathrm{~nm}$ was produced via a seed-growth 
method. TEM pictures and size distributions of all these AuNPs are available in Figure S1.

The resulting AuNPs- $\mathrm{X}_{4}-\mathrm{mix}(\%)$ were characterized by UV-vis, IR, and DLS. All these techniques showed the obtention of ultrastable and well-dispersed calixarene-coated AuNPs but could not help determining the proportion of $\mathrm{X}_{4}$ $(\mathrm{PEG})_{4}-\mathrm{COOH}$ and $\mathrm{X}_{4}-(\mathrm{PEG})_{4}$ at the NP surface. This latter was evaluated by measuring the amount of cyanine7.5 amine that could be covalently bound to the different batches of NPs. The conjugation of the dye and quantification of its grafting density were performed as described previously. Figure 6a a

AuNPs $+\mathrm{X}_{4}-(\mathrm{PEG})_{4}-\mathrm{COOH} / \mathrm{X}_{4}-(\mathrm{PEG})_{4}$
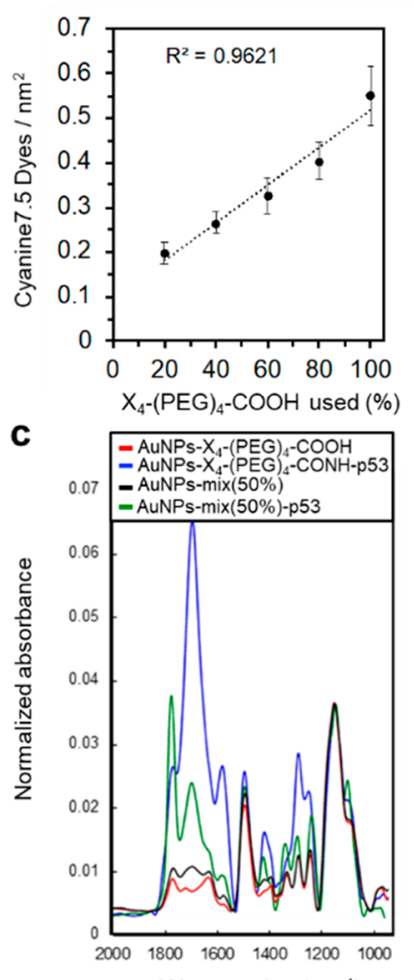

Wavenumber $\left(\mathrm{cm}^{-1}\right)$

\section{b}
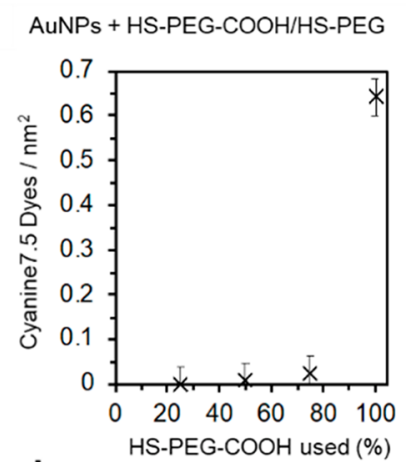

d

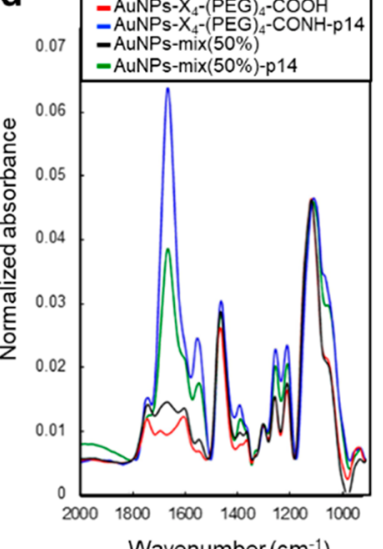

Wavenumber $\left(\mathrm{cm}^{-1}\right)$
Figure 6. (a) Average grafting density (dyes $/ \mathrm{nm}^{2}$ ) of the cyanine7.5 amine dye conjugated to AuNPs-mix $(x \%)$ produced from the different batches of AuNPs with different proportions of the two calix[4]arenes. (b) Average grafting density (dyes $/ \mathrm{nm}^{2}$ ) of the cyanine7.5 amine dye coupled on AuNPs-S-PEG/S-PEG-COOH. (c and d) Normalized ATR-FTIR spectra at $1100 \mathrm{~cm}^{-1}$ of AuNPs- $\mathrm{X}_{4^{-}}(\mathrm{PEG})_{4^{-}}$ $\mathrm{COOH}$ and AuNPs-mix (50\%) before and after conjugation of (c) p53 and (d) p14.

shows the average grafting densities obtained on batches of AuNPs functionalized with different proportions of the two calixarenes. Each conjugation experiment (i.e., for all the different investigated ratios) was repeated three times for each of the three different AuNP batches. Examples of UV-vis spectra obtained with AuNPs of $17 \mathrm{~nm}$ (Figure S1A) can be found in the SI (Figures S13). The conjugation of the cyanine7.5 amine dye was found to be proportional to the molar ratio of $\mathrm{X}_{4}-(\mathrm{PEG})_{4}-\mathrm{COOH}$ used in the functionalization solution. This result shows that the calixarene-based strategy allows a control over the number of bioconjugable groups at the surface of the NPs. For comparison purpose, we also grafted mixtures of two thioated PEG compounds, i.e. HS-
PEG-COOH and a nonconjugable one (HS-PEG), in different proportions (Figure $6 \mathrm{~b}$ ). We then conjugated the cyanine7.5 amine dye to these different batches of NPs under the same conditions than those used for the calixarene-coated particles. After washing of the particles, only the batch functionalized with $100 \%$ of HS-PEG-COOH showed the conjugation of a large amount of dyes. All the other AuNPs produced with mixtures of HS-PEG-COOH and HS-PEG showed almost no conjugated dyes. This result is in good agreement with previous studies reported in the literature ${ }^{34}$ and illustrates the extreme difficulty to control the density of functional groups at the surface of NPs by using mixtures of thiolated compounds.

Finally, we extended the conjugation of mixed layers to the coupling of the p53 and p14 peptides. As an example, Figures $6 \mathrm{c}$ and $6 \mathrm{~d}$ shows the IR spectra of AuNPs- $\mathrm{X}_{4}-(\mathrm{PEG})_{4}-\mathrm{COOH}$ compared to AuNPs-mix (50\%), conjugated to p53 or p14. The IR spectra have been normalized on the $\mathrm{C}-\mathrm{O}-\mathrm{C}$ stretching band, allowing the comparison of the intensities of the amide bands between the different samples. Again, the intensities of the amide I and II bands were proportional to the amount of $\mathrm{X}_{4}-(\mathrm{PEG})_{4}-\mathrm{COOH}$ used during the functionalization step. It clearly demonstrates the great potential of these calixarene-based particles in terms of control over the bioconjugation.

Application of AuNPs-mix to the Detection of Mdm2. As p53 and p14 can bind simultaneously to the cancer biomarker Mdm2, AuNPs-mix(50\%) functionalized with these peptides were used as colorimetric sensor for this protein. Indeed, the aggregation of AuNPs-mix(50\%)-p53 and AuNPs$\operatorname{mix}(50 \%)$-p14 in the presence of $\mathrm{Mdm} 2$ should lead to a change in the LSPR band of the AuNPs that can be quantitatively monitored by UV-vis spectroscopy (Figure 7). Three samples containing an equimolar suspension of AuNPs$\operatorname{mix}(50 \%)$-p53 and AuNPs-mix(50\%)-p14 were prepared, and their UV-vis spectra were recorded. Different volumes of a stock solution of $\mathrm{Mdm} 2$ (20 mM Tris. $\mathrm{HCl}, 100 \mathrm{mM} \mathrm{KCl}, \mathrm{pH}$ 7) were added to these suspensions in order to reach final target concentrations of 10,30 , and $50 \mathrm{nM}$. Note that this latter concentration corresponds to the physiological concentration of $\mathrm{Mdm} 2$. The UV-vis spectra of these suspensions were recorded after $40 \mathrm{~min}$ of stirring at room temperature. The aggregation level of the AuNPs was determined by measuring the difference between the $\mathrm{Abs}_{700 \mathrm{~nm}} / \mathrm{Abs}_{525 \mathrm{~nm}}$ ratios after and before the addition of $\mathrm{Mdm} 2$. A proportional relationship between these calculated differences and the concentration of Mdm2 was observed (Figure $7 \mathrm{~b}$ ). This variation of the LSPR band was specific to the addition of $\mathrm{Mdm} 2$, as a control experiment with the addition of $50 \mu \mathrm{M}$ of BSA (physiological blood concentration) did not show any variation of the LSPR band (Figures $7 \mathrm{~b}$ and S14). All these results show that the $\mathrm{p} 53$ and $\mathrm{p} 14$ peptides conjugated to $\operatorname{AuNPs}-\operatorname{mix}(50 \%)$ do not lose their recognition properties and that such AuNPs can be used for biosensing. Moreover, the limit of detection obtained was lower than the one of the previously reported thiolated system $(30 \mathrm{nM})^{44}$ as concentrations of $10 \mathrm{nM}$ could be identified with calix[4] arene-coated AuNPs, probably due to an improved conjugation of the peptides to the NPs.

\section{CONCLUSIONS}

Control over the composition of mixed layers of PEG chains is a big challenge in the functionalization of nanoparticles and a major limitation for applications requiring defined amounts of 
a

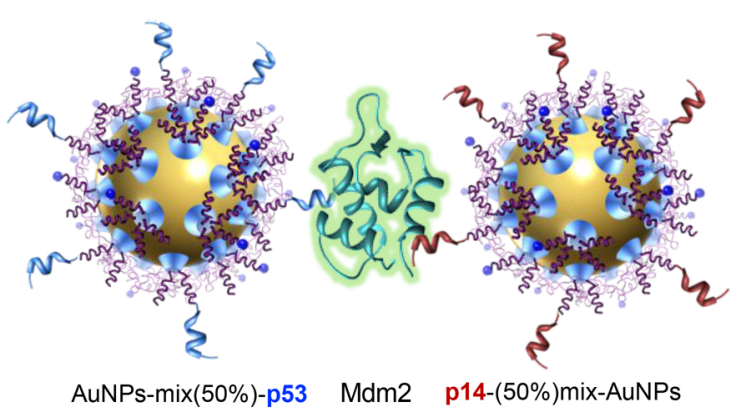

b

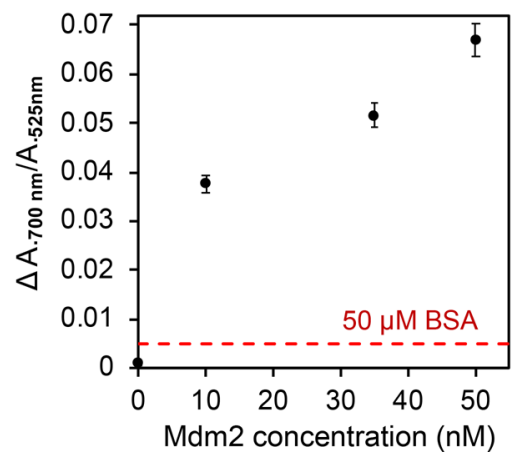

Figure 7. (a) Biosensor principle: the ternary complex between p53modified AuNPs, Mdm2, and p14-modified AuNPs leads to the aggregation of the particles and the generation of a colorimetric signal. (b) Difference between the ratio of Abs. $700 \mathrm{~nm}$ and Abs. $\lambda_{525}$ of the equimolar suspension of AuNPs-mix $(50 \%)$-p53 and AuNPs$\operatorname{mix}(50 \%)$-p14 after and before the addition of different concentrations of $\mathrm{Mdm} 2$. The red dashed line represents the value obtained after the addition of $50 \mu \mathrm{M}$ of BSA to the equimolar suspension of AuNPs-mix(50\%)-p53 and AuNPs-mix(50\%)-p14.

bioconjugable groups at their surface. This work describes a strategy that takes advantage of the remarkable properties of calix[4]arene-based platforms to achieve the robust PEGylation of gold nanoparticles with a tunable density of functional groups. We used either a bioconjugable calixarene carrying four PEG chains with one ended by a carboxyl group $\left(\mathrm{X}_{4}-(\mathrm{PEG})_{4}\right.$ $\mathrm{COOH})$ or a nonbioconjugable calixarene, carrying four PEG chains ended by a methoxy group $\left(\mathrm{X}_{4}-(\mathrm{PEG})_{4}\right)$. We demonstrated that the grafting of $\mathrm{X}_{4}-(\mathrm{PEG})_{4}-\mathrm{COOH}$ affords a strong protection to the particles thanks to the formation of a dense PEG layer, that is more robustly anchored to the surface than the conventionally used thiolated PEG chains. The presence of carboxyl groups allows the conjugation of aminecontaining molecules to these particles. Furthermore, we showed that the conjugation can be easily tuned by grafting mixed layers of $\mathrm{X}_{4}-(\mathrm{PEG})_{4}-\mathrm{COOH}$ and $\mathrm{X}_{4}-(\mathrm{PEG})_{4}$. Indeed, the grafting density of molecules containing an amino group that can be conjugated to the AuNPs is proportional to the molar fraction of $\mathrm{X}_{4}-(\mathrm{PEG})_{4}-\mathrm{COOH}$ used during the functionalization step of the AuNPs. Finally, these particles coated with mixtures of $\mathrm{X}_{4}-(\mathrm{PEG})_{4}-\mathrm{COOH}$ and $\mathrm{X}_{4}-(\mathrm{PEG})_{4}$ were functionalized with tunable amounts of peptide aptamers, p53 and p14, that have been designed for the detection of the cancer biomarker Mdm2. This result is particularly relevant as the grafting of p14 onto citrate-capped AuNPs was shown to be highly challenging due to its five positive charges. ${ }^{44} \mathrm{We}$ demonstrated that the aptamers conjugated to the calixarene-
AuNPs preserve their recognition properties but also that these particles can be dispersed in physiological fluids without showing any sign of aggregation. This opens the door to the development of in vitro diagnostic as well as in vivo applications, requiring defined amounts of biomolecules conjugated to AuNPs protected by a dense PEG layer. In addition, the sensitivity of our biosensor encompassed the one of the previously reported equivalent thiolated system. ${ }^{44}$ This extremely efficient and versatile functionalization strategy for AuNPs could easily be extended to other kinds of nanomaterials, as calix[4]arene-tetradiazonium salts are known to graft on various types of substrates (metals, semiconductors, polymers, glass). ${ }^{36}$ Future work in our laboratories is directed toward the preparation of such new calixarene-based nanomaterials as well as toward the development of orthogonally bioconjugated systems through the grafting of calix[4]arenes presenting different functional groups suitable for bioconjugation.

\section{EXPERIMENTAL SECTION}

General Materials. Potassium gold(III) tetrachloride $\left(\mathrm{KAuCl}_{4}\right)$, tetrachloroauric acid $\left(\mathrm{HAuCl}_{4}\right)$, and trisodium citrate $\left(\mathrm{Na}_{3} \mathrm{C}_{6} \mathrm{H}_{5} \mathrm{O}_{7}\right)$ were purchased from Sigma-Aldrich (StLouis, MO), and alpha-thio-omega-(propionic acid) octa(ethylene glycol) (HS-PEG-COOH, Mw $=458 \mathrm{Da}$ ) was ordered from Iris Biotech GMBH with a purity of $>95 \% .1 .5$ and $0.5 \mathrm{~mL}$ Protein LoBind eppendorf were purchased from VWR Chemical (Radnor, Pennsylvania). Cyanine7.5 amine dye (structure can be found in Figure S9b) was purchased from Lumiprobe (Hannover, Germany). Peptides p53 and p14 with a purity $>95 \%$ were purchased from Eurogentec (Liège, Belgium). Peptide sequences and structures are shown in Figure S11. Calix[4] arenes $\mathrm{X}_{4}-(\mathrm{PEG})_{4}$ was synthesized according to literature procedures. ${ }^{50}$ The synthesis of $\mathrm{X}_{4^{-}}$ $(\mathrm{PEG})_{4}-\mathrm{COOH}$ is detailed in the Supporting Information. Before use, all glassware and Teflon-coated stir bars were washed with aqua regia (3:1 volume ratio of concentrated $\mathrm{HCl}$ and $\mathrm{HNO}_{3}$ ) and rinsed thoroughly with water. Caution! Although we have not encountered any problem, it is noted that diazonium salt derivatives are potentially explosive and should be handled with appropriate precautions. Aqua regia is highly toxic and corrosive and requires proper personal protective equipment. Aqua regia should only be handled in a fume hood.

Gold Nanoparticle Synthesis. Two batches of citratecapped gold nanoparticles (AuNPs-citrate) were synthesized in an aqueous solution using a modified Turkevich method. ${ }^{51}$ Briefly, in a three-neck round-bottom flask, $1.4 \mathrm{~mL}$ of a $0.15 \mathrm{M}$ trisodium citrate solution were injected into $50 \mathrm{~mL}$ of boiling aqueous potassium gold(III) tetrachloride $(3 \mathrm{mM})$ at $\mathrm{pH} 7$. After addition, the reaction mixture changed from yellow to colorless, then to black, and finally to purple-red within $1 \mathrm{~min}$. The solution was kept under reflux for $5 \mathrm{~min}$ and then quenched to room temperature using cold water. The freshly synthesized AuNPs-citrate suspension was then dialyzed against a $1 \mathrm{mM}$ citrate solution for $12 \mathrm{~h}$, two times in a row.

One batch of AuNPs was synthesized in water via a seedsmediated growth method inspired by Piella et al. ${ }^{5}$ First, seeds were prepared by adding $1 \mathrm{~mL}$ of tetrachloroauric acid $\left(\mathrm{HAuCl}_{4}, 25 \mathrm{mM}\right)$ to $150 \mathrm{~mL}$ of sodium citrate $(2.2 \mathrm{mM})$, containing $1 \mathrm{~mL}$ of potassium carbonate $(150 \mathrm{mM})$ and 0.1 $\mathrm{mL}$ of tannic acid $(2.5 \mathrm{mM})$, at $70{ }^{\circ} \mathrm{C}$ under vigorous stirring. The color of the solution changed rapidly from colorless to 
black gray then to orange red in a few minutes. The solution was kept at $70{ }^{\circ} \mathrm{C}$ for $5 \mathrm{~min}$. Second, $55 \mathrm{~mL}$ of solution was removed from this suspension and replaced by $55 \mathrm{~mL}$ of trisodium citrate. When the temperature reached $70{ }^{\circ} \mathrm{C}$ again, two injections of $0.5 \mathrm{~mL}$ of $\mathrm{HAuCl}_{4}(25 \mathrm{mM})$ were performed at $10 \mathrm{~min}$ intervals. These two operations, i.e. sample dilution with trisodium citrate and injections of $\mathrm{HAuCl}_{4}$, were repeated 6 times until the particles reached the desired size. The freshly obtained AuNPs were then dialyzed against a $1 \mathrm{mM}$ sodium citrate solution for $12 \mathrm{~h}$, two times in a row. The size of the AuNPs was determined by TEM and the concentration by UV-vis spectroscopy, using the extinction coefficients reported by Liu et al. ${ }^{52} \mathrm{UV}$-vis spectra, TEM images, and size distribution histograms of the three batches of AuNPsCitrate can be found in the SI (Figure S1).

Calix[4]arenes Grafting on Gold Nanoparticles. $\mathrm{X}_{4}$ $(\mathrm{PEG})_{4}-\mathrm{COOH}$ and $\mathrm{X}_{4}-(\mathrm{PEG})_{4}$ were dissolved in water to prepare $10 \mathrm{mM}$ stock solutions. The $\mathrm{pH}$ of these solutions was adjusted to 5.5 by the addition of $\mathrm{NaOH}(1 \mathrm{M})$. It is worth mentioning that in the absence of this $\mathrm{pH}$ adjustment, the AuNPs strongly aggregated during the functionalization due to the too acidic conditions (Figure S2). Mixtures with a defined molar fraction of $\mathrm{X}_{4}-(\mathrm{PEG})_{4}-\mathrm{COOH}$ and $\mathrm{X}_{4}-(\mathrm{PEG})_{4}$ were prepared by mixing the appropriate volumes of the two mother solutions. The general procedure for the grafting was the following: $12 \mu \mathrm{L}$ of $\mathrm{NaBH}_{4}(0.1 \mathrm{M})$ was added to $1 \mathrm{~mL}$ of AuNPs-citrate $(16 \mathrm{nM})$ under vigorous stirring in a glass vial containing a stir bar. Quickly after this, $200 \mu \mathrm{L}$ of the $10 \mathrm{mM}$ calix [4] arene solutions were added slowly (approximately $20 \mathrm{~s}$ for the complete addition) and the resulting suspension was stirred overnight. During the reaction, the $\mathrm{pH}$ was around 7.5. The nanoparticles were afterward cleaned by centrifugation (20 $\mathrm{min}$ at $18.000 \mathrm{~g}$ ) and the supernatants replaced by an equivalent volume of water. This process was repeated four times to obtain a dilution factor of the soluble species of $5 \times$ $10^{6}$. It is noteworthy that the first supernatant was replaced by a $5 \mathrm{mM} \mathrm{NaOH}$ water solution. This was necessary to properly resuspend the particles.

Conjugation of the AuNPs-calix[4]arenes with the Cyanine 7.5 Dye. In a LoBind Eppendorf, AuNPs were diluted in a phosphate buffer $(50 \mathrm{mM} ; \mathrm{pH} 6)$ in order to reach a NP concentration of $2 \mathrm{nM}$ in a volume of $300 \mu \mathrm{L} .100 \mu \mathrm{L}$ of DMSO was then added to ensure the solubility of the dye. To this, EDC ( $1 \mathrm{mg}, 5 \mu \mathrm{mol})$ and sulfo-NHS $(2 \mathrm{mg}, 9 \mu \mathrm{mol})$ were added, and the resulting suspension was stirred in a thermomixer at $1000 \mathrm{rpm}$. After a few minutes, an appropriate volume of the cyanine 7.5 amine dye (approximately $400 \mu \mathrm{M}$ in DMSO) was added to reach approximately 5000 dyes per particle. The temperature was then increased to $50{ }^{\circ} \mathrm{C}$, and the final mixture was stirred at $1000 \mathrm{rpm}$ for $4 \mathrm{~h}$. It is worth mentioning that the cyanine7.5 amine dye solution in DMSO was prepared highly concentrated so that the volume added was negligible compared to the total volume. At the end of the reaction, the AuNPs were cleaned from excess reagents and dyes by four cycles of centrifugation, removing of the supernatant and replacement of this latter by aqueous SDS solution (1\% in mass). This washing step with SDS ensured the almost complete removal of dyes that would be physically adsorbed on the surface of the AuNPs.

Conjugation of the AuNPs-calix[4]arenes with Peptides. In a $1.5 \mathrm{~mL}$ LoBind Eppendorf, AuNPs were diluted in a phosphate buffer ( $50 \mathrm{mM} ; \mathrm{pH} 6)$ in order to reach a NP concentration of $2 \mathrm{nM}$ in a volume of $800 \mu \mathrm{L} .100 \mu \mathrm{L}$ of EDC
(6 $\mathrm{mM}$ in water) and $100 \mu \mathrm{L}$ of sulfo-NHS (10 mM in water) were then added to the AuNPs, and the resulting suspension was placed in a thermomixer and stirred at $1000 \mathrm{rpm}$. A few minutes later, $50 \mu \mathrm{L}$ of the peptide solution ( $200 \mu \mathrm{M}$ in water) were added to the AuNPs to reach approximately 5000 peptides per particle and the final mixture was stirred at room temperature overnight. At the end of the reaction, the AuNPs were cleaned from excess reagents and peptides by four cycles of centrifugation, removing the supernatant and replacement of this latter by first an aqueous SDS solution (1\% in mass) (2 cycles) and then water ( 2 cycles).

Conjugation Quantification. The amount of cyanine7.5 amine dyes conjugated to AuNPs was obtained by UV-vis spectroscopy using the following procedure:

(i) the total absorbance at $805 \mathrm{~nm}$ was measured. It corresponds to the sum of the absorbance of the dye and of the absorbance of the particles;

(ii) the contribution of the AuNPs at $805 \mathrm{~nm}$ was obtained with a polynomial fit of the absorption spectrum using the 630-660 and 900-1000 nm intervals, where the contribution of the dye to the total absorbance is negligible;

(iii) the dye contribution at $805 \mathrm{~nm}$ was obtained by subtracting (ii) from (i), and the dye concentration was obtained thanks to its extinction coefficient at that wavelength $\left(223.000 \mathrm{~L} \cdot \mathrm{mol}^{-1} \cdot \mathrm{cm}^{-1}\right)$;

(iv) the amount of dye adsorbed onto the particles and not covalently conjugated was obtained by performing steps (i), (ii), and (iii) with the results obtained for a control experiment performed in the absence of EDC/sulfoNHS reagents;

(v) the amount of dyes covalently conjugated to the AuNPs is obtained by subtracting (iv) from (iii) and by comparing this concentration to the AuNP concentration determined by their absorbance at $\lambda \max$ (around $520 \mathrm{~nm}$ ) and their extinction coefficient.

Mdm2 Detection. In a $0.5 \mathrm{~mL}$ protein LoBind Eppendorf, an equimolar suspension of $\operatorname{AuNPs-mix}(50 \%)$-p53 and AuNPs-mix(50\%)-p14 was prepared in a volume of $100 \mu \mathrm{L}$ and a UV-vis spectrum was recorded. To this, an appropriate volume of a stock solution of $\mathrm{Mdm} 2$ ( $300 \mathrm{nM}$ in $20 \mathrm{mM}$ Tris. $\mathrm{HCl}$ and $100 \mathrm{mM} \mathrm{KCl}, \mathrm{pH} \mathrm{7)}$ was added in order to reach final target concentrations of 10,30 , and $50 \mathrm{nM}$. The UV-vis spectrum of the resulting suspensions was recorded after 40 min of stirring at room temperature. The aggregation level of the AuNPs was determined by measuring the difference between the Abs. $700 \mathrm{~nm} / \mathrm{Abs} .525 \mathrm{~nm}$ ratios after and before the addition of $\mathrm{Mdm} 2$.

UV-vis Spectroscopy. UV-vis absorption spectra were recorded from 1000 to $300 \mathrm{~nm}$ at a $120 \mathrm{~nm} / \mathrm{min}$ scan speed with a UV-vis-NIR spectrophotometer in disposable (PMMA) cuvettes with a $1 \mathrm{~cm}$ optical path length at room temperature.

Dynamic Light Scattering. Samples were characterized by dynamic light scattering (DLS) with back scattering (NIBS $\left.173^{\circ}\right)$. Measurements were performed at $25{ }^{\circ} \mathrm{C}$ using a refractive index of 1.54 for the gold nanoparticles. AuNPs (20 $\mu \mathrm{L}, \sim 16 \mathrm{nM})$ were dispersed in lichrosolv water to obtain 1 $\mathrm{mL}$ of AuNPs $(\sim 0.16 \mathrm{nM})$ in disposable semimicro cuvettes (PMMA), and multiple DLS measurements were performed. The reported values are the average hydrodynamic diameters 
obtained from three independent measurements using the $\mathrm{Z}$ average as calculated by the Zetasizer software.

Attenuated Total Reflection Fourier-Transform Infrared. Attenuated total reflection Fourier-transform infrared (ATR-FTIR) spectra were recorded at $22{ }^{\circ} \mathrm{C}$ on a FTIR spectrophotometer equipped with a liquid-nitrogen-cooled mercury-cadmium-telluride detector. The spectrophotometer was continuously purged with dried air. The target chemicals were deposited in solution on a germanium singlecrystal internal reflection element (triangular prism of $6.8 \times 45$ $\mathrm{mm}$, with an internal incidence angle of $45^{\circ}$ ), and the solvent was removed with a flow of nitrogen gas. Bare germanium was used for the background spectrum. Opus software (4.2.37) was used to record 128 scans with a nominal resolution of $2 \mathrm{~cm}^{-1}$. Data were processed and analyzed using the home written Kinetics package in Matlab R2013a by subtraction of water vapor, baseline correction, and apodization at $10 \mathrm{~cm}^{-1}$.

Thermogravimetric Analysis. The thermogravimetric analyses (TGA) were performed on a TA Instruments Q5000 TGA with air as purge gas $(25 \mathrm{~mL} / \mathrm{min})$. A suspension of AuNPs in $40 \mu \mathrm{L}$ water was placed in a DSC crucible (Tzero), and the water was evaporated in a vacuum oven by slowly decreasing the pressure and increasing the temperature. When the dark red liquid had turned into a gold colored film, the crucible was further dried for $30 \mathrm{~min}$ at $10 \mathrm{mbar}$ and $75^{\circ} \mathrm{C}$. The crucible was loaded in the TGA instrument and a $2 \mathrm{~h}$ isotherm was measured at $60{ }^{\circ} \mathrm{C}$, followed by a linear ramp up to $600{ }^{\circ} \mathrm{C}$ at a rate of $10^{\circ} \mathrm{C} / \mathrm{min}$, a $60 \mathrm{~min}$ isotherm at $600{ }^{\circ} \mathrm{C}$, cooling, and another $2 \mathrm{~h}$ isotherm at $60^{\circ} \mathrm{C}$. The loss of organic material was obtained from the difference in weight at the plateaus of the $60^{\circ} \mathrm{C}$ isotherms (average of last $20 \mathrm{~min}$ ) before and after heating.

Transmission Electron Microscopy. Images of the AuNPs were obtained with a Philips CM20-UltraTWIN transmission electron microscope (TEM) equipped with a lanthanum hexaboride (LaB6) crystal at a $200 \mathrm{kV}$ accelerating voltage. The average size and $95 \%$ confidence interval were determined by measuring the size of more than 100 AuNPs.

\section{ASSOCIATED CONTENT}

\section{SI Supporting Information}

The Supporting Information is available free of charge at https://pubs.acs.org/doi/10.1021/acs.bioconjchem.0c00669.

UV-vis spectra, TEM images and size-distribution histograms of AuNPs; pictures of AuNPs- $\mathrm{X}_{4}-(\mathrm{PEG})_{4}$ $\mathrm{COOH}$ suspensions; ATR-FTIR spectrum of $\mathrm{X}_{4^{-}}$ $(\mathrm{PEG})_{4}-\mathrm{COOH}$; TGA curves; DLS analyses; procedure for the preparation of AuNPs-S-PEG-COOH; IR spectrum and UV-vis characterization of the conjugation to the cyanine7.5 amine dye; UV-vis spectrum of AuNPs- $\mathrm{X}_{4}-(\mathrm{PEG})_{4}$-COOH suspended in human serum; UV-vis spectrum and structure of the cyanine7.5 amine dye; peptides sequences and corresponding ATRFTIR spectra; UV-vis spectra of AuNPs-mix(\%) conjugated to the cyanine7.5 amine dye; UV-vis spectra related to $\mathrm{Mdm} 2$ detection; procedures for the synthesis of $\mathrm{X}_{4}$-(PEG) $)_{4} \mathrm{COOH}$ and corresponding NMR spectra. (PDF)

\section{AUTHOR INFORMATION}

\section{Corresponding Authors}

Ivan Jabin - Laboratoire de Chimie Organique, Université libre de Bruxelles (ULB), B-1050 Brussels, Belgium; ○ orcid.org/0000-0003-2493-2497; Email: Ivan.Jabin@ ulb.be

Gilles Bruylants - Engineering of Molecular NanoSystems, Ecole Polytechnique de Bruxelles, Université libre de Bruxelles (ULB), B-1050 Brussels, Belgium; 이이.org/0000-00031752-5826; Email: gbruylan@ulb.ac.be

\section{Authors}

Maurice Retout - Engineering of Molecular NanoSystems, Ecole Polytechnique de Bruxelles, Université libre de Bruxelles (ULB), B-1050 Brussels, Belgium

Pascale Blond - Laboratoire de Chimie Organique, Université libre de Bruxelles (ULB), B-1050 Brussels, Belgium

Complete contact information is available at:

https://pubs.acs.org/10.1021/acs.bioconjchem.0c00669

\section{Notes}

The authors declare the following competing financial interest(s): M.R. has been a postdoctoral researcher for X4C (https://x4c.eu/) since August 2020. I.J. is a shareholder of X4C. I.J. and G.B. are consultants for X4C.

\section{ACKNOWLEDGMENTS}

The "Actions de Recherches Concertées" of the Fédération Wallonie-Bruxelles and the ULB (Ph.D. grant to M. R. and P.B.) are acknowledged for financial support.

\section{REFERENCES}

(1) Saha, K., Agasti, S. S., Kim, C., Li, X., and Rotello, V. M. (2012) Gold Nanoparticles in Chemical and Biological Sensing. Chem. Rev. $112,2739-2779$.

(2) Zhou, W., Gao, X., Liu, D., and Chen, X. (2015) Gold Nanoparticles for in Vitro Diagnostics. Chem. Rev. 115, 10575-10636.

(3) Elahi, N., Kamali, M., and Baghersad, M. H. (2018) Recent Biomedical Applications of Gold Nanoparticles: A Review. Talanta 184, 537-556.

(4) Chen, Y., Xianyu, Y., and Jiang, X. (2017) Surface Modification of Gold Nanoparticles with Small Molecules for Biochemical Analysis. Acc. Chem. Res. 50, 310-319.

(5) Piella, J., Bastús, N. G., and Puntes, V. (2016) Size-Controlled Synthesis of Sub-10-Nanometer Citrate-Stabilized Gold Nanoparticles and Related Optical Properties. Chem. Mater. 28, 1066-1075.

(6) Kelly, K. L., Coronado, E., Zhao, L. L., and Schatz, G. C. (2003) The Optical Properties of Metal Nanoparticles: The Influence of Size, Shape, and Dielectric Environment. J. Phys. Chem. B 107, 668-677.

(7) Jain, P. K., Huang, X., El-Sayed, I. H., and El-Sayed, M. A. (2007) Review of Some Interesting Surface Plasmon ResonanceEnhanced Properties of Noble Metal Nanoparticles and Their Applications to Biosystems. Plasmonics 2, 107-118.

(8) Kumar, A., Ma, H., Zhang, X., Huang, K., Jin, S., Liu, J., Wei, T., Cao, W., Zou, G., and Liang, X.-J. (2012) Gold Nanoparticles Functionalized with Therapeutic and Targeted Peptides for Cancer Treatment. Biomaterials 33, 1180-1189.

(9) Majzik, A., Fülöp, L., Csapó, E., Bogár, F., Martinek, T., Penke, B., Bíró, G., and Dékány, I. (2010) Functionalization of Gold Nanoparticles with Amino Acid, Beta-Amyloid Peptides and Fragment. Colloids Surf., B 81, 235-241.

(10) Zong, J., Cobb, S. L., and Cameron, N. R. (2017) PeptideFunctionalized Gold Nanoparticles: Versatile Biomaterials for Diagnostic and Therapeutic Applications. Biomater. Sci. 5, 872-886. 
(11) Jazayeri, M. H., Amani, H., Pourfatollah, A. A., Pazoki-Toroudi, H., and Sedighimoghaddam, B. (2016) Various Methods of Gold Nanoparticles (GNPs) Conjugation to Antibodies. Sens. Bio-Sensing Res. 9, 17-22.

(12) Zhang, C., Wu, R., Li, Y., Zhang, Q., and Yang, J. (2017) Programmable Regulation of DNA Conjugation to Gold Nanoparticles via Strand Displacement. Langmuir 33, 12285-12290.

(13) Mohd-Zahid, M. H., Mohamud, R., Che Abdullah, C. A., Lim, J., Alem, H., Wan Hanaffi, W. N., and Iskandar, Z. A. (2020) Colorectal Cancer Stem Cells: A Review of Targeted Drug Delivery by Gold Nanoparticles. RSC Adv. 10, 973-985.

(14) Kong, F. Y., Zhang, J. W., Li, R. F., Wang, Z. X., Wang, W. J., and Wang, W. (2017) Unique Roles of Gold Nanoparticles in Drug Delivery, Targeting and Imaging Applications. Molecules 22, 1445.

(15) Yao, C., Zhang, L., Wang, J., He, Y., Xin, J., Wang, S., Xu, H., and Zhang, Z. (2016) Gold Nanoparticle Mediated Phototherapy for Cancer. J. Nanomater. 2016, 29.

(16) Amendoeira, A., García, L. R., Fernandes, A. R., and Baptista, P. V. (2020) Light Irradiation of Gold Nanoparticles Toward Advanced Cancer Therapeutics. Adv. Ther. 3, 1900153.

(17) Song, J., Kim, J., Hwang, J., Jeon, M., Jeong, S., Kim, C., and Kim, S. (2016) Smart" Gold Nanoparticles for Photoacoustic Imaging: An Imaging Contrast Agent Responsive to the Cancer Microenvironment and Signal Amplification via PH-Induced Aggregation. Chem. Commun. 52, 8287-8290.

(18) Iranpour, P., Ajamian, M., Safavi, A., Iranpoor, N., Abbaspour, A., and Javanmardi, S. (2018) Synthesis of Highly Stable and Biocompatible Gold Nanoparticles for Use as a New X-Ray Contrast Agent. J. Mater. Sci.: Mater. Med. 29, 48.

(19) Liu, X., Wang, Y., Chen, P., Wang, Y., Zhang, J., Aili, D., and Liedberg, B. (2014) Biofunctionalized Gold Nanoparticles for Colorimetric Sensing of Botulinum Neurotoxin A Light Chain. Anal. Chem. 86, 2345-2352.

(20) Lapenna, A., Dell'Aglio, M., Palazzo, G., and Mallardi, A. (2020) Naked" Gold Nanoparticles as Colorimetric Reporters for Biogenic Amine Detection. Colloids Surf., A 600, 124903.

(21) Fales, A. M., Vogt, W. C., Pfefer, J., and Ilev, I. K. (2017) Quantitative Evaluation of Nanosecond Pulsed Laser-Induced Photomodification of Plasmonic Gold Nanoparticles. Sci. Rep. 7, 1-11.

(22) Dimitriou, N. M., Tsekenis, G., Balanikas, E. C., Pavlopoulou, A., Mitsiogianni, M., Mantso, T., Pashos, G., Boudouvis, A. G., Lykakis, I. N., Tsigaridas, G., Panayiotidis, M. I., Yannopapas, V., and Georgakilas, A. G. (2017) Gold Nanoparticles, Radiations and the Immune System: Current Insights into the Physical Mechanisms and the Biological Interactions of This New Alliance towards Cancer Therapy. Pharmacol. Ther. 178, 1-17.

(23) Eghtedari, M., Liopo, A. V., Copland, J. A., Oraevsky, A. A., and Motamedi, M. (2009) Engineering of Hetero-Functional Gold Nanorods for the in Vivo Molecular Targeting of Breast Cancer Cells. Nano Lett. 9, 287-291.

(24) Lin, L. K., Uzunoglu, A., and Stanciu, L. A. (2018) Aminolated and Thiolated PEG-Covered Gold Nanoparticles with High Stability and Antiaggregation for Lateral Flow Detection of Bisphenol A. Small $14,1-10$.

(25) Chen, X. Y., Ha, W., and Shi, Y. P. (2019) Sensitive Colorimetric Detection of Melamine in Processed Raw Milk Using Asymmetrically PEGylated Gold Nanoparticles. Talanta 194, 475484.

(26) Manson, J., Kumar, D., Meenan, B. J., and Dixon, D. (2011) Polyethylene Glycol Functionalized Gold Nanoparticles: The Influence of Capping Density on Stability in Various Media. Gold Bull. 44, 99-105.

(27) Jokerst, J. V., Lobovkina, T., Zare, R. N., and Gambhir, S. S. (2011) Nanoparticle PEGylation for Imaging and Therapy. Nanomedicine 6, 715-728.

(28) Niidome, T., Yamagata, M., Okamoto, Y., Akiyama, Y., Takahashi, H., Kawano, T., Katayama, Y., and Niidome, Y. (2006) PEG-Modified Gold Nanorods with a Stealth Character for in Vivo Applications. J. Controlled Release 114, 343-347.
(29) Häkkinen, H. (2012) The Gold-Sulfur Interface at the Nanoscale. Nat. Chem. 4, 443-455.

(30) Badia, A., Demers, L., and Dickinson, L. (1997) Gold-Sulfur Interactions in Alkylthiol Self-Assembled Monolayers Formed on Gold Nanoparticles Studied by Solid-State NMR. J. Am. Chem. Soc. 119, 11104-11105.

(31) Shumbula, N. P., Ndala, Z. B., Nkabinde, S. S., Kolokoto, T., Shumbula, P. M., Mdluli, P. S., Hlatshwayo, T., Mlambo, M., and Moloto, N. (2020) Experimental and Theoretical Studies of 1Alkanethiols SAMs of Various Chain-Lengths on Gold Nanoparticles and Their Effect on SERS, Stability and Surface Properties. J. Mol. Struct. 1221, 128801.

(32) Kreyling, W., Abdelmonem, A., Ali, Z., Alves, F., Geiser, M., Haberl, N., Hartmann, R., Hirn, S., Jimenez de Aberasturi, D., Kantner, K., Khadem-Saba, G., Montenegro, J.-M., Rejman, J., Rojo, T., Ruiz de Larramendi, I., Ufartes, R., Wenk, A., and Parak, W. J. (2015) In vivo integrity of polymer-coated gold nanoparticles. Nat. Nanotechnol. 10, 619-623.

(33) Zhang, G., Yang, Z., Lu, W., Zhang, R., Huang, Q., Tian, M., Li, L., Liang, D., and Li, C. (2009) Influence of Anchoring Ligands and Particle Size on the Colloidal Stability and in Vivo Biodistribution of Polyethylene Glycol-Coated Gold Nanoparticles in Tumor-Xenografted Mice. Biomaterials 30, 1928-1936.

(34) Retout, M., Brunetti, E., Valkenier, H., and Bruylants, G. (2019) Limits of Thiol Chemistry Revealed by Quantitative Analysis of Mixedlayers of Thiolated-PEG Ligands Grafted onto Gold Nanoparticles. J. Colloid Interface Sci. 557, 807-815.

(35) Pinson, J., and Podvorica, F. (2005) Attachment of Organic Layers to Conductive or Semiconductive Surfaces by Reduction of Diazonium Salts. Chem. Soc. Rev. 34, 429-439.

(36) Troian-Gautier, L., Mattiuzzi, A., Reinaud, O., Lagrost, C., and Jabin, I. (2020) Use of Calixarenes Bearing Diazonium Groups for the Development of Robust Monolayers with Unique Tailored Properties. Org. Biomol. Chem. 18, 3624-3637.

(37) Troian-Gautier, L., Martínez-Tong, D. E., Hubert, J., Reniers, F., Sferrazza, M., Mattiuzzi, A., Lagrost, C., and Jabin, I. (2016) Controlled Modification of Polymer Surfaces through Grafting of Calix[4]Arene-Tetradiazoate Salts. J. Phys. Chem. C 120, 2293622945.

(38) Mattiuzzi, A., Jabin, I., Mangeney, C., Roux, C., Reinaud, O., Santos, L., Bergamini, J. F., Hapiot, P., and Lagrost, C. (2012) Electrografting of Calix[4]Arenediazonium Salts to Form Versatile Robust Platforms for Spatially Controlled Surface Functionalization. Nat. Commun. 3, 3.

(39) Adenier, A., Combellas, C., Kanoufi, F., Pinson, J., and Podvorica, F. I. (2006) Formation of Polyphenylene Films on Metal Electrodes by Electrochemical Reduction of Benzenediazonium Salts. Chem. Mater. 18, 2021-2029.

(40) Troian-Gautier, L., Valkenier, H., Mattiuzzi, A., Jabin, I., Den Brande Van, N., Mele Van, B., Hubert, J., Reniers, F., Bruylants, G., Lagrost, C., and Leroux, Y. (2016) Extremely Robust and PostFunctionalizable Gold Nanoparticles Coated with Calix[4]Arenes via Metal-Carbon Bonds. Chem. Commun. 52, 10493-10496.

(41) Santos, L., Mattiuzzi, A., Jabin, I., Vandencasteele, N., Reniers, F., Reinaud, O., Hapiot, P., Lhenry, S., Leroux, Y., and Lagrost, C. (2014) One-Pot Electrografting of Mixed Monolayers with Controlled Composition. J. Phys. Chem. C 118, 15919-15928.

(42) Valkenier, H., Malytskyi, V., Blond, P., Retout, M., Mattiuzzi, A., Goole, J., Raussens, V., Jabin, I., and Bruylants, G. (2017) Controlled Functionalization of Gold Nanoparticles with Mixtures of Calix[4]Arenes Revealed by Infrared Spectroscopy. Langmuir 33, 8253.

(43) Shaikh, M. F., Morano, W. F., Lee, J., Gleeson, E., Babcock, B. D., Michl, J., Sarafraz-Yazdi, E., Pincus, M. R., and Bowne, W. B. (2016) Emerging Role of MDM2 as Target for Anti-Cancer Therapy: A Review. Ann. Clin. Lab. Sci. 46, 627-634.

(44) Retout, M., Valkenier, H., Triffaux, E., Doneux, T., Bartik, K., and Bruylants, G. (2016) Rapid and Selective Detection of Proteins 
by Dual Trapping Using Gold Nanoparticles Functionalized with Peptide Aptamers. ACS Sensors 1, 929-933.

(45) Ghosh, H., and Bürgi, T. (2017) Mapping Infrared Enhancement around Gold Nanoparticles Using Polyelectrolytes. J. Phys. Chem. C 121, 2355-2363.

(46) Hinterwirth, H., Kappel, S., Waitz, T., Prohaska, T., Lindner, W., and Lämmerhofer, M. (2013) Quantifying Thiol Ligand Density of Self-Assembled Monolayers on Gold Nanoparticles by Inductively Coupled Plasma-Mass Spectrometry. ACS Nano 7, 1129-1136.

(47) Orefuwa, S. A., Ravanbakhsh, M., Neal, S. N., King, J. B., and Mohamed, A. A. (2014) Robust Organometallic Gold Nanoparticles. Organometallics 33, 439-442.

(48) De La Llave, E., Ricci, A., Calvo, E. J., and Scherlis, D. A. (2008) Binding between Carbon and the $\mathrm{Au}(111)$ Surface and What Makes It Different from the S-Au(111) Bond. J. Phys. Chem. C 112, 17611-17617.

(49) Laurentius, L., Stoyanov, S. R., Gusarov, S., Kovalenko, A., Du, R., Lopinski, G. P., and McDermott, M. T. (2011) DiazoniumDerived Aryl Films on Gold Nanoparticles: Evidence for a CarbonGold Covalent Bond. ACS Nano 5, 4219-4227.

(50) Blond, P., Mattiuzzi, A., Valkenier, H., Troian-Gautier, L., Bergamini, J. F., Doneux, T., Goormaghtigh, E., Raussens, V., and Jabin, I. (2018) Grafting of Oligo(Ethylene Glycol)-Functionalized Calix[4]arene-Tetradiazonium Salts for Antifouling Germanium and Gold Surfaces. Langmuir 34, 6021-6027.

(51) Doyen, M., Bartik, K., and Bruylants, G. (2013) UV-Vis and NMR Study of the Formation of Gold Nanoparticles by Citrate Reduction: Observation of Gold-Citrate Aggregates. J. Colloid Interface Sci. 399, 1-5.

(52) Liu, X., Atwater, M., Wang, J., and Huo, Q. (2007) Extinction Coefficient of Gold Nanoparticles with Different Sizes and Different Capping Ligands. Colloids Surf., B 58, 3-7. 